\title{
Metaplastic Facilitation and Ultrastructural Changes in Synaptic Properties Are Associated with Long-Term Modulation of the Lamprey Locomotor Network
}

\author{
Sarah Bevan and David Parker \\ Department of Zoology, University of Cambridge, Cambridge CB2 3EJ, United Kingdom
}

The neuropeptide substance $\mathrm{P}$ evokes a long-term protein synthesis-dependent increase in the cycle frequency of locomotor network activity in the lamprey. Although cellular and synaptic mechanisms that could induce this effect have been identified, nothing is known of the underlying maintenance mechanisms. These mechanisms have been examined here.

Substance P potentiates low-frequency-evoked EPSPs from excitatory network interneurons. It also converts the depression of the EPSP during spike trains into facilitation, an example of metaplasticity. The metaplasticity was associated with a reduction of the transmitter release probability but an increase in the number of release sites. Although the potentiation of low-frequency-evoked EPSPs recovered within $1 \mathrm{hr}$, the metaplastic facilitation had not recovered 3-4 hr after substance P application. The metaplasticity thus extended into the protein synthesis-dependent maintenance phase of the network modulation, making it the only identified cellular or synaptic effect of substance $P$ to last this long. It also had the same induction and maintenance features as the network burst frequency modulation, further suggesting that the two effects were related.

Long-term changes in synaptic properties are often associated with changes in synaptic organization. We have thus also examined the effects of substance $P$ on synaptic ultrastructure up to $5 \mathrm{hr}$ after substance $P$ application. Substance $P$ had several significant effects. These included an increase in the number of docked vesicles and a reduction of the synaptic gap.

Substance $\mathrm{P}$ thus has long-term effects on synaptic organization and function. The relevance of these effects to the long-term locomotor network modulation is discussed.

Key words: spinal cord; synaptic plasticity; network; lamprey; metaplasticity; synaptic ultrastructure

\section{Introduction}

The mechanisms underlying long-term synaptic plasticity are among the most intensively studied aspects in neuroscience (Milner et al., 1998). Long-term plasticity could contribute to changes during development or learning (Feldman et al., 1999; Martin et al., 2000), or to functional recovery after injury (Chen et al., 2002). Studies of long-term plasticity in the vertebrate CNS have focused on long-term potentiation (LTP) and long-term depression (Bear and Malenka, 1994). Although information is available on the cellular mechanisms that induce these effects, there is still some uncertainty over the mechanisms underlying their maintenance (Malenka and Nicoll, 1999).

In the lamprey spinal cord, a single $10 \mathrm{~min}$ application of the neuropeptide substance $\mathrm{P}$ evokes a long-term $(>24 \mathrm{hr})$ increase in the frequency of locomotor network activity (Parker, 2000a). This effect is induced by the protein kinase $\mathrm{C}(\mathrm{PKC})$-mediated modulation of NMDA receptors and increased $\mathrm{Ca}^{2+}$ levels in network neurons. Its induction thus resembles certain forms of

\footnotetext{
Received May 27, 2003; revised Sept. 13, 2004; accepted Sept. 13, 2004.

This work was supported by the Royal Society and the Biotechnology and Biological Sciences Research Council.

Correspondence should be addressed to Dr. David Parker, Department of Zoology, Cambridge University, Downing Street, Cambridge CB2 3EJ, UK. E-mail: djp27@cam.ac.uk.

DOI:10.1523/JNEUROSCI.3391-04.2004

Copyright $\odot 2004$ Society for Neuroscience $\quad$ 0270-6474/04/249458-11\$15.00/0
}

LTP (Malenka and Nicoll, 1999). The induction phase lasts for $\sim 2 \mathrm{hr}$ and is followed by an intermediate maintenance phase $(\sim 2-15 \mathrm{hr})$ that appears to require protein synthesis, but not $d e$ novo RNA synthesis, and a late maintenance phase $(>15 \mathrm{hr})$ that does require RNA synthesis (Parker, 2000a).

Substance P potentiates low-frequency-evoked EPSPs from glutamatergic excitatory network interneurons (EINs). This effect is mediated postsynaptically by the PKC-dependent modulation of NMDA responses and presynaptically through the facilitation of glutamate release (Parker, 2000a). The EPSP potentiation usually recovers within $1 \mathrm{hr}$ of substance $\mathrm{P}$ application, and thus it cannot account for the long-term maintenance of the burst frequency modulation. Substance P has several other cellular and synaptic effects (Parker, 2000a). However, these are also transient and thus cannot account for the maintenance of the network modulation.

Although single low-frequency-evoked PSPs are typically used to examine synaptic modulation, this pattern of stimulation does not mimic the synaptic input during network activity (Buchanan and Cohen, 1982; Buchanan and Kasicki, 1995). The effects of substance $\mathrm{P}$ were thus examined on synaptic inputs evoked by physiologically relevant spike trains. Substance P usually converted the activity-dependent depression of EIN-evoked EPSPs into facilitation (Parker, 2000a). This effect was not asso- 
ciated with a reduction of the initial EPSP amplitude, which may be expected to reduce depression (Zucker and Regehr, 2002), and thus provides an example of metaplasticity, the plasticity of activity-dependent plasticity (Abraham and Bear, 1996). The properties of this metaplastic facilitation were not studied and have thus been examined in detail here. The results suggest a link between the synaptic metaplasticity and the network modulation. Because long-term changes in synaptic function are associated with changes in synaptic organization (Lisman and Harris, 1993), we also examined the effects of substance $\mathrm{P}$ on synaptic ultrastructure. Substance P had several effects that could provide a morphological basis for the synaptic and network modulation. Changes in synaptic organization and function thus appear to contribute to the long-term modulation of the locomotor network output.

\section{Materials and Methods}

Male and female adult lampreys (Lampetra fluviatilis, $n=191$; Icthyomyzon unicuspis, $n=15$ ) were used in this study. Substance P evokes longterm network modulation in both species (Parker and Grillner, 1999a). Because no species-dependent differences were found in the analyses performed here, the results from the two species were grouped.

Animals were anesthetized with tricaine methane sulfonate (MS-222), and the spinal cord and notochord were removed from between the last gill and the beginning of the dorsal fin (i.e., the trunk region of the body; $\sim 40$ segments).

Electrophysiology. For experiments involving intracellular recordings, the spinal cord was isolated from the notochord and placed ventral side up in a Sylgard-lined chamber. The connective tissue and meninx primitiva were removed from the ventral surface. A plastic net was placed over the surface of the spinal cord and pinned into the Sylgard to stabilize the cord. The spinal cord was superfused with Ringer's solution containing (in mM) $138 \mathrm{NaCl}, 2.1 \mathrm{KCl}, 1.8 \mathrm{CaCl}_{2}, 1.8 \mathrm{MgCl}_{2}, 4$ glucose, 2 HEPES, and 0.5 L-glutamine, which was bubbled with $\mathrm{O}_{2}$ and $\mathrm{pH}$ adjusted to 7.4. The experimental chamber was kept at a temperature of $10-12^{\circ} \mathrm{C}$.

Paired intracellular recordings were made from the somata of identified EINs and motor neurons using thin- or thick-walled glass micropipettes filled with $3 \mathrm{~m}$ potassium acetate and $0.1 \mathrm{M}$ potassium chloride (resistances of 40-60 M $\Omega$ ). EINs were located in the same segment or one segment rostral to the postsynaptic motor neuron. Motor neurons were identified by recording orthodromic spikes in the corresponding ventral root after current injection into their somata and EINs by their ability to elicit monosynaptic EPSPs in ipsilateral motor neurons. Monosynaptic connections were identified by their reliability and constant latency after presynaptic stimulation at $20 \mathrm{~Hz}$. An Axoclamp 2B amplifier (Axon Instruments, Foster City, CA) was used for amplification and in discontinuous current-clamp mode for current injection. Action potentials were evoked by injecting $1 \mathrm{msec}$ depolarizing current pulses of 10-60 nA. pClamp 8 software (Axon Instruments) was used for data acquisition and analysis on a computer equipped with an analog-todigital interface (Digidata 1322; Axon Instruments). The membrane potential of the postsynaptic cell was kept at $-70 \mathrm{mV}$ throughout the experiment by current injection using discontinuous current clamp.

The analysis of synaptic effects that could contribute to the maintenance of the long-term burst frequency modulation required that synaptic transmission was examined for at least $2-3 \mathrm{hr}$ after substance P application, i.e., at a time when the protein synthesis-dependent maintenance phase had begun (Parker et al., 1998). EIN cell bodies are relatively small $(\sim 10 \mu \mathrm{m}$ in diameter) (Buchanan et al., 1989), and thus long-term recordings from these cells are extremely rare. Long-term changes in synaptic properties were instead examined by comparing the properties of different EINs before and $4 \mathrm{hr}$ after substance $\mathrm{P}$ application. A technique was also developed that allowed the long-term analysis of synaptic transmission from single EINs. Once an EIN had been identified, a thin-tipped glass suction electrode was placed on the surface of the spinal cord above the EIN. The lamprey spinal cord is thin $(200-250 \mu \mathrm{m})$, and this was presumably why in, albeit relatively few, favorable cases varying the elec- trode position and the stimulus strength and duration could evoke a spike in the recorded EIN and an EPSP in the postsynaptic cell that matched that evoked by intracellular EIN stimulation (see Fig. $1 E$ ). This suggested that only the recorded EIN had been activated and meant that extracellular stimulation could be used to examine long-term changes of identified EIN-evoked EPSPs. Experiments were discontinued if there were marked changes in the properties of the extracellularly evoked input (e.g., a sudden increase or decrease in the EPSP amplitude) that suggested either failure to stimulate the original EIN or the recruitment of other cells or axons.

Activity-dependent metaplasticity was examined using presynaptic stimulation trains of 20 spikes evoked at $20 \mathrm{~Hz}$ (Parker and Grillner, 1999b). The spike trains were evoked at $30 \mathrm{sec}$ intervals. EPSP amplitudes were measured from the baseline immediately preceding the EPSP to the peak of the EPSP. At $20 \mathrm{~Hz}$ there is little or no summation of the EPSPs (see Fig. $1 \mathrm{~B}$ ). Plasticity was examined over the second to fifth EPSPs ( $\left.\operatorname{Train}_{2-5}\right)$, the sixth to 10th EPSPs (Train ${ }_{6-10}$ ), and the 11th to 20th EPSPs ( Train $_{11-20}$ ) in the train. The EPSPs over these regions of the spike train were averaged, and the averaged values compared with the initial EPSP amplitude to quantify the plasticity $\left(\mathrm{EPSP}_{\text {Train }} / \mathrm{EPSP}_{\text {Initial }}\right)$. Depression of the synaptic input was defined as a sustained reduction of the EPSP amplitude to at least $90 \%$ of control over the spike train and facilitation as a sustained increase of the EPSP amplitude to $>110 \%$ of the initial PSP amplitude. Connections in which the EPSP amplitude did not fall below $90 \%$ or above $110 \%$ of the initial EPSP amplitude during the train were defined as unchanged (i.e., exhibited no activity-dependent plasticity). Connections in which the EPSP amplitude fluctuated above $110 \%$ or below $90 \%$ of the initial EPSP amplitude, but in which there was no consistent change during the spike train, were also classified as unchanged. Where connections depressed ( $66 \%$ of connections examined here) or were unchanged in control (25\% of connections examined here), metaplastic facilitation was defined as a change to facilitation after substance P application. When connections facilitated in control (9\% of connections examined here), metaplastic facilitation was considered to have occurred if there was at least a $10 \%$ increase in the level of facilitation by substance $P$.

Synaptic properties were examined using a variance-mean (V-M) analysis (Clements and Silver, 2000; Parker, 2003). This method examines the EPSP variance and mean under conditions of altered release probability caused by high- and low-calcium Ringer's solution. Calcium was reduced to $50 \%$ of control in low-calcium Ringer's solution and increased to $200 \%$ in high-calcium Ringer's solution. At lower release probabilities in low-calcium Ringer's solution, fewer sites release transmitter, and the EPSP amplitude and variance are reduced. At high release probabilities, almost all sites release transmitter. This increases the EPSP amplitude but again reduces the variance. At intermediate release probabilities, the number of sites that release transmitter fluctuates from trial to trial. This results in intermediate EPSP amplitudes and an increased variance. The relationship of the variance to the mean at different release probabilities can be approximated by a parabola, and from this the transmitter release probability $\left(p_{\mathrm{w}}\right)$, quantal amplitude $\left(q_{\mathrm{w}}\right)$, and minimum number of release sites $\left(N_{\min }\right)$ can be calculated (for details, see Clements and Silver, 2000). One hundred EPSPs were evoked at $0.2 \mathrm{~Hz}$ in normal, high-calcium, and low-calcium Ringer's solution (Parker, 2003). This frequency of stimulation did not evoke any activity-dependent change in the EPSP amplitude over the stimulation period (see Fig. 4Aii). The different Ringer's solutions were in the bath for $5 \mathrm{~min}$ before recordings were made. This is sufficient time for the Ringer's solution changes to take effect. Synaptic properties were compared in separate EIN-motor neuron $(\mathrm{MN})$ connections in control and $4 \mathrm{hr}$ after substance $\mathrm{P}$ application.

The PKC antagonist chelerythrine and the NMDA receptor antagonist AP-5 were applied for 10 min before recordings were made (Parker et al., 1998). The protein synthesis inhibitors anisomycin and 5,6dichlorobenzimidazole riboside (DRB) were applied for $1 \mathrm{hr}$ before recordings were made (Parker and Grillner, 1999a). Substance P (1 $\mu \mathrm{M})$ was applied for $10 \mathrm{~min}$ in all experiments (Parker et al., 1998). Drugs and altered Ringer's solutions were applied continuously before, during, and 
after substance $\mathrm{P}$ application. Numbers in the text refer to the number of synaptic connections examined.

Electron microscopy. Changes in synaptic ultrastructure were examined in five animals (Lamptera fluviatilis). Two to four pieces of spinal cord left attached to the notochord were taken from each animal and placed in NMDA $(50 \mu \mathrm{M})$ to evoke network activity. Because NMDA-evoked activity can vary dramatically in the first hour after its application, cords were left for at least $2 \mathrm{hr}$ before the experiment started. Treated cords were exposed to substance P $(1 \mu \mathrm{M})$ for $10 \mathrm{~min}$ to evoke the long-term network modulation (Parker et al., 1998). In three animals, separate pieces of spinal cord were fixed $30 \mathrm{~min}, 3 \mathrm{hr}$, and $5 \mathrm{hr}$ after substance $\mathrm{P}$ application. In the fourth animal, the pieces of cord were fixed $30 \mathrm{~min}$ and $5 \mathrm{hr}$ after substance $\mathrm{P}$ application, and in the fifth animal, the cord was fixed $3 \mathrm{hr}$ after substance $\mathrm{P}$ application. Control pieces of cord from each animal were only exposed to $50 \mu \mathrm{M}$ NMDA and were fixed in parallel with the substance P-treated cord samples.

The pieces of spinal cord were transferred to $3 \%$ glutaraldehyde in 0.1 M phosphate buffer, $\mathrm{pH} 7.4$, and fixed at $4^{\circ} \mathrm{C}$ overnight. The samples were washed in $0.1 \mathrm{M}$ phosphate buffer, $\mathrm{pH} 7.4$, and postfixed in buffered $1 \%$ $\mathrm{OsO}_{4}$ for $1 \mathrm{hr}$. After washing in $0.1 \mathrm{M}$ phosphate buffer, the samples were dehydrated through an ethanol series, transferred to propylene oxide for two 15 min washes, and embedded in Araldite CY212 (Agar Scientific). Ultrathin sections were cut in cross section on a Reichert OmU2 microtome and mounted on uncoated copper mesh grids. The sections were counterstained with uranyl acetate and lead citrate and visualized using a Phillips EM 300 electron microscope. Each section contained the cell body region of the spinal cord. All synapses photographed were within this region. No attempt was made to label specific interneurons because this can prevent the analysis of presynaptic properties (Buchanan et al., 1989).

Micrograph negatives were scanned at 1200 dots per inch using an Epson Perfection 2450 Photo scanner. The scanned images were imported into Adobe Photoshop for measurement of synaptic properties. The following features were examined: the total number of synaptic vesicles; the vesicle morphology (round, flattened, or pleomorphic, i.e., vesicles with irregular sizes and shapes) (Peters et al., 1991); the number of docked vesicles (defined as vesicles that were in contact with the presynaptic membrane); the upper and lower vesicle diameters; the number of presynaptic and postsynaptic mitochondria within $1 \mu \mathrm{m}$ of the presynaptic or postsynaptic density (PSD); the size of the synaptic gap (determined by averaging measurements from three regions at each connection); and the continuity and length of the PSD. The PSD can be continuous (see Fig. 5A) or perforated (see Fig. 5C). Our measurements of the total length of the PSD included continuous and perforated PSDs, but in perforated synapses, only the PSD regions were measured. In a very limited number of cases, PSDs sharing the same presynaptic and postsynaptic terminals were far apart ( $n=3$ of 357 synapses measured) or were separated by a protrusion that originated from the presynaptic cell $(n=2$ of 357). These effects were not obviously related to an effect of substance $\mathrm{P}$ or the time after substance $\mathrm{P}$ application, because they could occur in control and treated cords. In cases in which there was a protrusion or in which the distance between the PSDs was at least twice the mean PSD length in the terminal, the structure was assumed to be two separate synaptic compartments, not a perforated synapse (Sorra et al., 1998). Synapses were also characterized on the basis of their PSDs (symmetrical, asymmetrical, or intermediate, i.e., connections that were not obviously asymmetric or symmetric), the location of the synapse onto the postsynaptic cell (i.e., onto a dendritic shaft, a dendritic spine or the cell body), and shape of the synapse (whether the postsynaptic site was wrapped or partially wrapped by the presynaptic terminal, or if it was of "simple" form, i.e., with no wrapping). Examples of the morphological features are shown in Figure 5. Random sample sections were analyzed blind a second time to ensure that there was no unconscious bias in the analysis of properties in control and treated sections. The total numbers of synapses analyzed were as follows: 106 controls; 71 at 30 min after substance $\mathrm{P}$ application, 88 at $3 \mathrm{hr}$ after substance $\mathrm{P}$ application, and 92 at $5 \mathrm{hr}$ after substance $\mathrm{P}$ application. The data presented were pooled data from the five animals.
Statistical analyses. Statistical significance was examined using paired or unpaired $t$ tests, one-way ANOVA (or the Kruskal-Wallis test, for nonparametric comparisons), or Fisher's exact test or $\chi^{2}$ test. Values in the text represent mean \pm SEM.

\section{Results}

Substance P ( $1 \mu \mathrm{M}$ bath applied for $10 \mathrm{~min}$ ) presynaptically and postsynaptically potentiates low-frequency-evoked EPSPs from glutamatergic EINs (Parker, 2000a). It also converts the depression of the EPSP during spike trains into facilitation, an example of metaplasticity (i.e., a change in activity-dependent synaptic properties) (Fig. $1 A, B)$. Metaplasticity occurred in $\sim 60 \%$ of connections examined in this study $(n=19$ of $32 ; n=10$ of 17 Lamptera and 9 of 15 Icthyomyzon), a comparable percentage as seen previously (Parker and Grillner, 1999b). In these experiments, the metaplasticity occurred in 14 connections that depressed in control, in 4 connections that were unchanged, and in 1 connection that facilitated. There was no obvious relationship of plasticity to the failures, metaplasticity failing to occur in seven depressing connections, four unchanged connections, and two facilitating connections. The absence of the effect at every connection is presumably related to the variable properties of EIN synapses in control (Parker, 2003). This suggests that the EINs do not form a functionally homogeneous population of interneurons and thus may have different potentials for modulation. We have examined the relevance of the metaplastic facilitation to the network burst frequency modulation.

For the metaplasticity to contribute to the maintenance of the burst frequency modulation, it must extend into the protein synthesis-dependent maintenance phase (i.e., $>2-3 \mathrm{hr}$ after substance $\mathrm{P}$ application). The initial aim was thus to determine the duration of the metaplasticity. When paired recordings were maintained for at least 30-45 min after substance P application, the initial EPSP amplitude had either recovered to control or showed a trend to recovery $(n=5$ of 6$)$ (Fig. $1 B)$. In contrast, recovery of the metaplasticity at this time only occurred in one of six experiments. This result showed that the metaplasticity outlasted the potentiation of low-frequency-evoked EPSPs, but it did not establish whether it extended into the protein synthesisdependent maintenance phase of the network modulation. To determine this, EIN synaptic properties had to be examined for at least $2 \mathrm{hr}$ after substance $\mathrm{P}$ application. Paired intracellular recordings lasting this long were not possible, and thus two alternative approaches were used to examine the duration of the metaplasticity. First, the properties of different EINs to motor neuron connections were compared before and $4 \mathrm{hr}$ after substance $\mathrm{P}$ application. The amplitude of the initial EPSP in the trains did not differ significantly at these times (Fig. 1C) $(1.2 \pm$ $0.4 \mathrm{mV}$ before substance $\mathrm{P}, n=285 ; 1.12 \pm 0.5 \mathrm{mV} 4 \mathrm{hr}$ after substance $\mathrm{P}, n=35 ; p>0.1$ ), which was consistent with the lack of a long-term change in the amplitude of low-frequency-evoked EPSPs. However, there was a significant change in the activitydependent properties of connections $4 \mathrm{hr}$ after substance $\mathrm{P}$ application. In the total sample size of EIN-MN connections (Parker, 2003), 61 of 225 connections (27\%) facilitated during the spike train in control, whereas of the connections examined here $4 \mathrm{hr}$ after substance $\mathrm{P}$ application, 21 of 35 facilitated (60\%) (Fig. 1D) $\left(p<0.0001 ; \chi^{2}\right.$ test). This increase in the proportion of facilitating connections was mirrored by a significant reduction in the proportion of depressing connections from $47 \%$ to $22 \%$ ( $p<$ $0.0001 ; \chi^{2}$ test) (Fig. 1D). 
This analysis suggested a long-term metaplastic effect of substance $\mathrm{P}$ on the activity-dependent plasticity of EIN-evoked synaptic transmission. Direct evidence that would support the presence of long-term metaplastic facilitation was also sought by stimulating identified EINs extracellularly (see Materials and Methods) (Fig. 1E). Although these experiments had a low success rate, it was possible to stimulate single EINs extracellularly in five experiments. In four of five of these experiments, substance $\mathrm{P}$ significantly increased the amplitude of the initial EPSP $(p<$ 0.05 ) and evoked significant metaplastic facilitation over all regions of the spike train $(p<0.05)$ (Fig. 1 Fi,Fii). Before substance $\mathrm{P}$ application, the connections where metaplasticity occurred either depressed $(n=3)$ or showed no plasticity $(n=1)$. Although the potentiation of the initial EPSP usually recovered to control within $1 \mathrm{hr}$ of substance $\mathrm{P}$ application $(n=3$ of 4$)$, significant metaplasticity persisted $3 \mathrm{hr}$ after the start of substance $\mathrm{P}$ washoff ( $n=4$ of 4 ) (Fig. 1 Fi,Fii). This result also supports a longterm metaplastic effect of substance $\mathrm{P}$ on EIN synaptic transmission.

Metaplasticity was not a general feature of glutamatergic synaptic transmission. Although substance $\mathrm{P}$ can potentiate the amplitude of low-frequency-evoked EPSPs from glutamatergic reticulospinal axons (Parker and Grillner, 1998), it did not evoke metaplastic facilitation over spike trains at frequencies of $5-20 \mathrm{~Hz}$ $(n=9)$. Depression was instead usually enhanced (Fig. 1Gi,Gii). Because activity-dependent plasticity is often inversely related to the initial PSP amplitude in the spike train (Zucker and Regehr, 2002), depression would be greater when the initial PSP was larger, possibly because the increased transmitter release on the initial PSP reduces the amount of transmitter available for subsequent PSPs. The potentiation of the initial reticulospinal-evoked EPSP by substance P, rather than metaplasticity, could thus account for the enhanced depression of reticulospinal inputs. Metaplasticity was also not a general feature of network synaptic transmission. Substance P could alter the activity-dependent plasticity of inputs from small ipsilateral inhibitory

interneurons to motor neurons and unidentified spinal cord neurons (D. Parker, unpublished observations). However, these effects were again associated with changes in the initial IPSP amplitude; depression was enhanced when the initial IPSP was potentiated but reduced when the initial IPSP was reduced. Because these effects can be accounted for by changes in the initial IPSP, they again probably do not represent actual metaplasticity.

\section{The relationship of metaplastic facilitation to the long-term network modulation}

The metaplastic facilitation of EIN synaptic transmission is the only identified cellular or synaptic effect of substance $P$ that persists into the protein synthesis-dependent maintenance phase of the network burst frequency modulation (Parker, 2000a). Although any maintenance effect must outlast the induction phase, a maintenance mechanism cannot be identified on the basis of its duration alone: it must have properties that are consistent with a role in the network modulation. Information was available on the induction and maintenance properties of the network burst frequency modulation (Parker, 2000a). This allowed the mechanisms of the synaptic metaplasticity to be compared with the network modulation.

The specific PKC antagonist chelerythrine $(10 \mu \mathrm{M})$ blocks the induction of the network burst frequency modulation (Parker et al., 1998). The effect of chelerythrine on the metaplasticity was examined by making paired intracellular recordings from EINs and motor neurons. Significant substance P-mediated metaplas- tic facilitation occurred in five of eight experiments in the presence of chelerythrine (10 $\mu \mathrm{M})$ (Parker et al., 1998) (Fig. 2Ai), the other connections showing no change in activity-dependent properties. The proportion of connections in which metaplastic facilitation occurred in the presence of chelerythrine did not differ significantly to the proportion of connections in which it occurred when chelerythrine was absent $\left(p>0.05 ; \chi^{2}\right.$ test). However, in chelerythrine, substance $P$ failed to evoke significant metaplastic facilitation over $\operatorname{Train}_{2-5}(p>0.05$; one-way ANOVA; $n=5$ ) (Fig. $2 \mathrm{~A} i$ ), and the facilitation over latter regions of the spike train usually recovered to control between 10 and 30 min after substance $\mathrm{P}$ application $(n=4$ of 5$)$ (Fig. $2 A i)$. These effects were not normally associated with the substance P-mediated metaplasticity, and thus chelerythrine reduced the magnitude and duration of the metaplastic facilitation during spike trains. Chelerythrine also blocked the potentiation of the initial EPSP amplitude by substance P (Fig. 2Aii); substance P instead resulted in a transient $(<30 \mathrm{~min})$ nonsignificant reduction of the initial EPSP amplitude $(p>0.05 ; n=6$ of 8 ) (Fig. 2 Aii). Because facilitation tends to develop when the initial EPSPs are smaller (Parker, 2003), the transient facilitation evoked by substance $\mathrm{P}$ in chelerythrine may have reflected the reduction of the initial EPSP amplitude and not metaplasticity per se.

The PKC-mediated potentiation of NMDA responses is central to the induction of the burst frequency modulation (Parker 2000a). Although the NMDA receptor antagonist AP-5 failed to block the metaplastic facilitation of EIN inputs in preliminary experiments (Parker and Grillner, 1999b), its effects were only examined up to $10 \mathrm{~min}$ after substance $\mathrm{P}$ application. The longterm consequences of NMDA receptor blockade on the metaplastic facilitation were thus examined here. Substance P could evoke some metaplastic facilitation in 5 of 12 experiments in the presence of AP-5 (100 $\mu \mathrm{M})$. Although this proportion of connections again did not differ significantly to the proportion of connections in which substance $\mathrm{P}$ evoked metaplastic facilitation in the absence of AP-5 ( $p>0.05 ; \chi^{2}$ test $)$, the metaplasticity was only significant over $\operatorname{Train}_{6-10}$ and had decayed by $30 \mathrm{~min}$ after substance $\mathrm{P}$ application ( $n=4$ of 4 ) (Fig. $2 \mathrm{Bi}$ ). AP-5 thus also reduced the metaplastic effects of substance $P$. Substance $P$ could still result in significant short-term potentiation of the initial EPSP amplitude in AP-5 ( $n=7$ of $12 ; p<0.05)$ (Fig. 2Bii), presumably as a result of the presynaptic facilitation of glutamate release by substance P (Parker and Grillner, 1998).

The substance P-mediated increase in the network burst frequency is calcium dependent (Parker, 2000a). The role of calcium in the metaplastic facilitation was examined by applying substance P in low-calcium Ringer's solution. This Ringer's solution reduced the initial EPSP amplitude by $\sim 50 \%$ (Fig. 2Cii) and either reduced the depression during the spike train or evoked facilitation (Parker, 2000b) (Fig. 2Ci). Although substance P could significantly increase the initial EPSP amplitude in lowcalcium Ringer's solution ( $n=4$ of $5 ; p<0.05$ ) (Fig. 2Cii), it did not alter the activity-dependent properties of any connection during the spike train (Fig. $2 C i)(n=5$ of $5 ; p>0.05$; one-way ANOVA), thus suggesting that the metaplastic facilitation was calcium dependent.

The metaplasticity was thus blocked or reduced by PKC inhibitors, by NMDA receptor antagonists, and by low-calcium Ringer's solution. This suggests that the substance P-mediated metaplasticity shares the PKC, NMDA, and calcium-dependent induction properties of the network burst frequency modulation. 


\section{Maintenance mechanisms}

In common with most long-term changes in the nervous system (Bailey et al., 1996), the burst frequency modulation is dependent on protein synthesis for its maintenance. The analysis of the effects of substance $\mathrm{P}$ on network activity suggested that there are two phases of protein synthesis (Parker, 2000a). The initial phase develops 2-3 hr after substance P application and is blocked by translation inhibitors, but not by transcription inhibitors or by disrupting the Golgi complex, suggesting that protein synthesis may occur locally in cells from presynthesized mRNA. The later phase develops 15-20 hr after substance $\mathrm{P}$ application and is blocked by transcription inhibitors and by disrupting the Golgi complex, suggesting that it requires genomic activation and Golgi processing. The long-term metaplastic facilitation should share these features if it contributes to the maintenance of the network modulation.

Because the protein synthesis-dependent maintenance phase of the network modulation does not develop until at least $2 \mathrm{hr}$ after substance $\mathrm{P}$ application, long-term stimulation of identified EINs was needed to examine the effects of protein synthesis inhibitors on the metaplasticity. Substance P-mediated metaplastic facilitation occurred in five of seven experiments in the presence of the translation inhibitors anisomycin (10 $\mu \mathrm{M} ; n=2$ of 4$)$ or puromycin (10 $\mu \mathrm{M} ; n=3$ of 3 ) (Parker et al., 1998). The extracellular stimulation technique used had a low success rate. Because both of these translation inhibitors block the maintenance, but not induction, of the network burst frequency modulation, the results obtained in experiments using these inhibitors were grouped. The proportion of connections in which metaplasticity was evoked in translation inhibitors did not differ significantly to the proportion of connections in which metaplasticity occurred when translation inhibitors were absent $\left(p>0.05 ; \chi^{2}\right.$ test $)$. However, the metaplasticity had usually decayed within 1-2 hr after substance $\mathrm{P}$ application ( $n=4$ of 5 ) (Fig. $3 A$ ).

Metaplasticity was evoked in the presence of the transcription inhibitor DRB (10 $\mu \mathrm{M} ; n=4$ of 5 ) (Parker and Grillner, 1999b), which blocks the late (>15 hr) maintenance phase of the network modulation but not its induction or the initial (2-15 hr) maintenance phase (Parker and Grillner, 1999b). The metaplasticity evoked in DRB was maintained $3 \mathrm{hr}$ after substance $\mathrm{P}$ application $(n=4)$ (Fig. $3 B)$, which suggested that de novo RNA
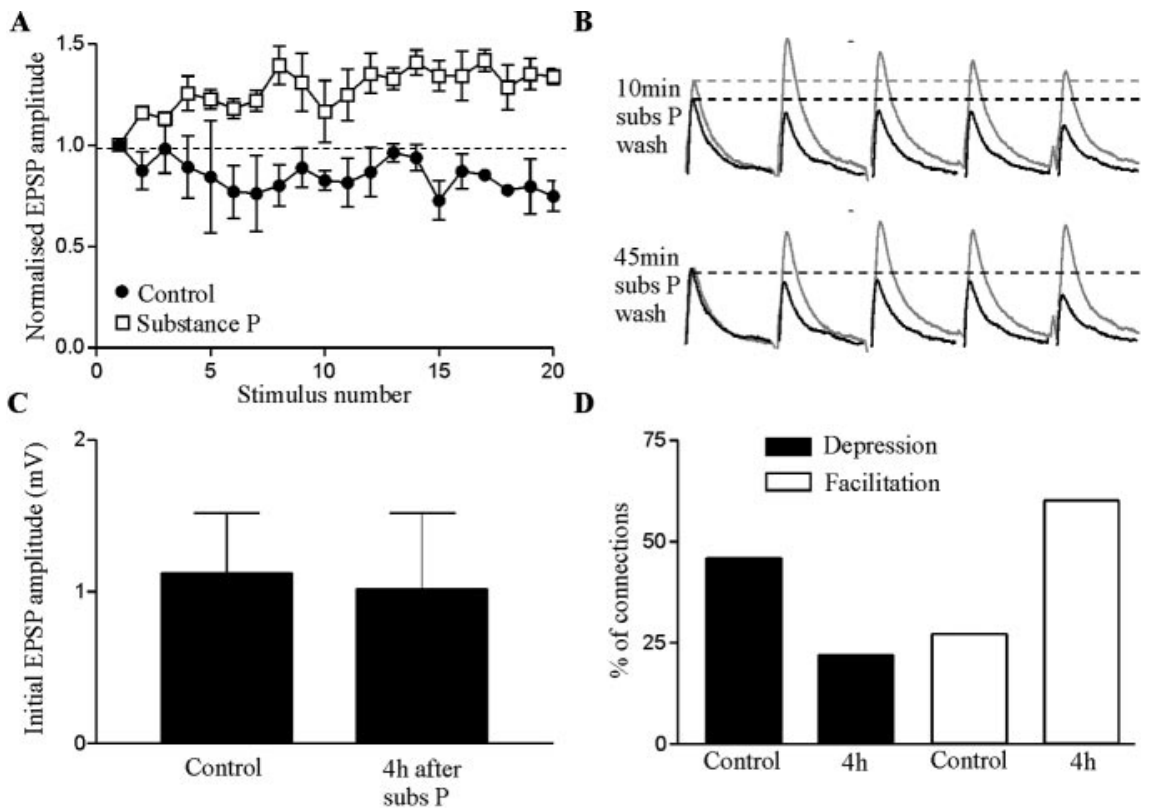

$\mathbf{E}$
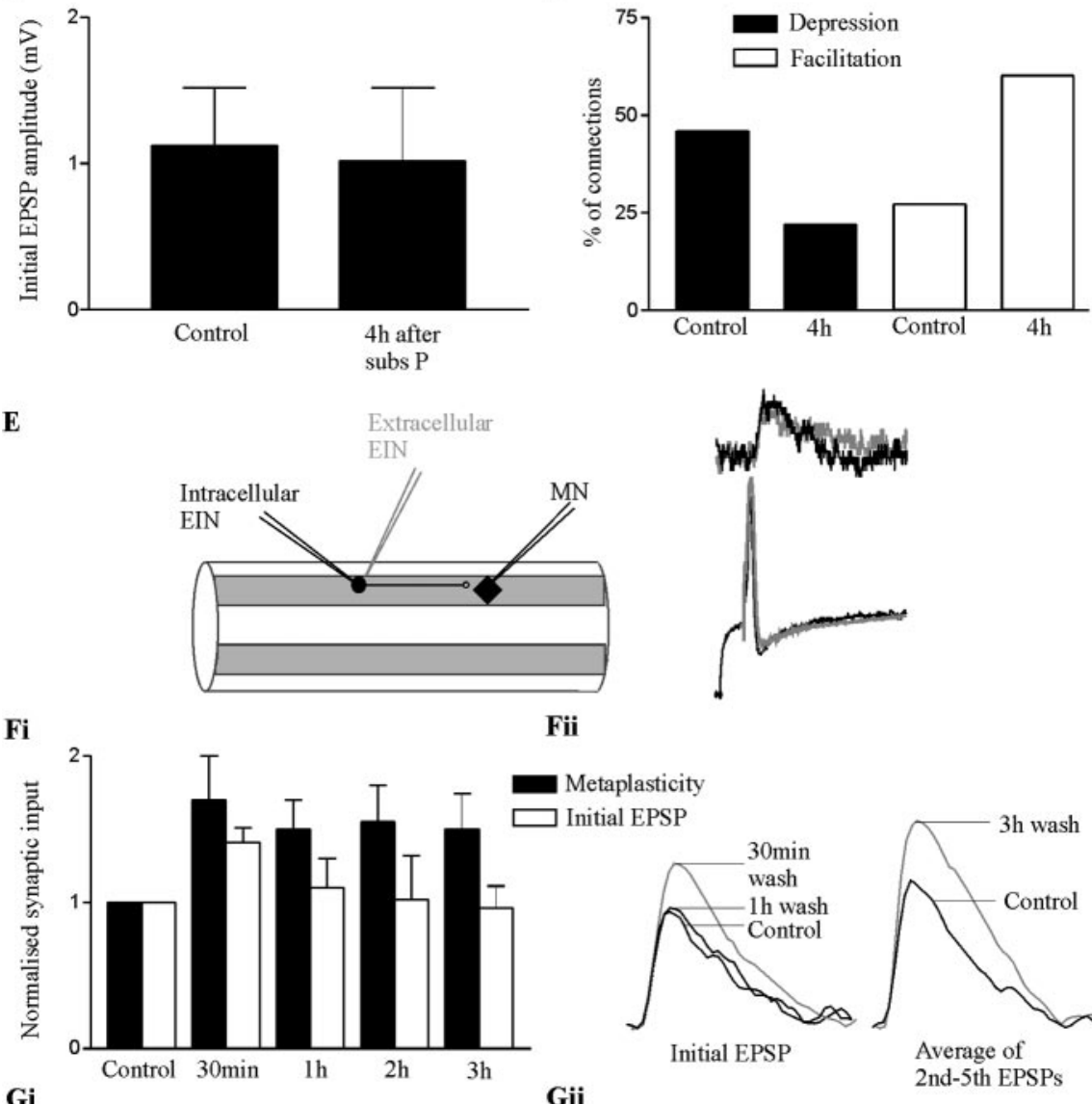

Metaplasticity Initial EPSP
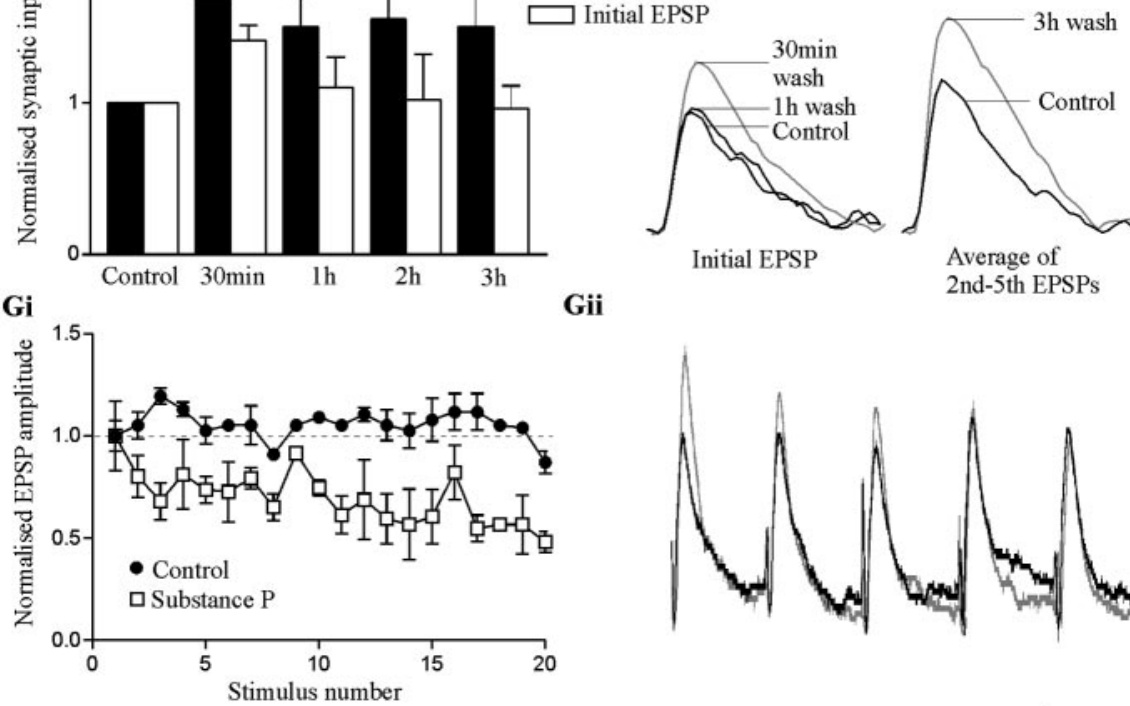

Gii

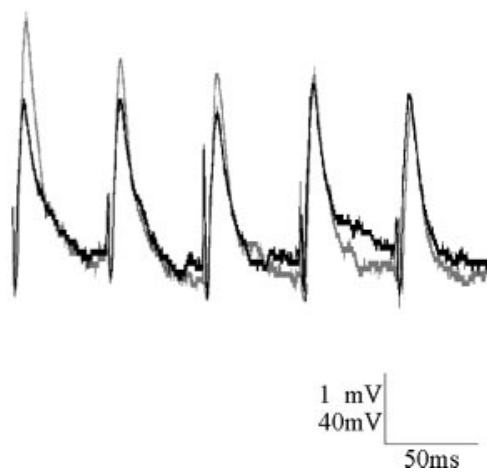

Figure 1. Substance $P$ evokes long-term metaplastic facilitation of EIN-evoked EPSPs. A, An example of the metaplastic facilitation evoked by substance $P$ at a single EIN to motor neuron connection. The EIN input depressed in control (black circles; average of 9 spike trains) but was facilitated in substance $P$ (white squares; average of 9 spike trains). In all cases, metaplasticity was examined using trains of 20 presynaptic spikes evoked at $20 \mathrm{~Hz}$. B, Traces from another EIN to motor neuron connection showing the potentiation of the initial EPSP in the train and the metaplastic facilitation 10 min after the start of substance $P$ (subs P) wash-off. Note that the potentiation of the initial EPSP amplitude, but not the metaplastic facilitation, had recovered after washing for $45 \mathrm{~min}$. All traces are averages of 10 sweeps. Gray lines show the input after substance $P$ and black lines the control response. C, Comparison of the initial EIN-evoked EPSP amplitude in different EIN to motor neuron connections before and $4 \mathrm{hr}$ after substance $P$ application. $D$, Graph showing the proportion of facilitating and depressing EIN connections before $(n=225)$ 

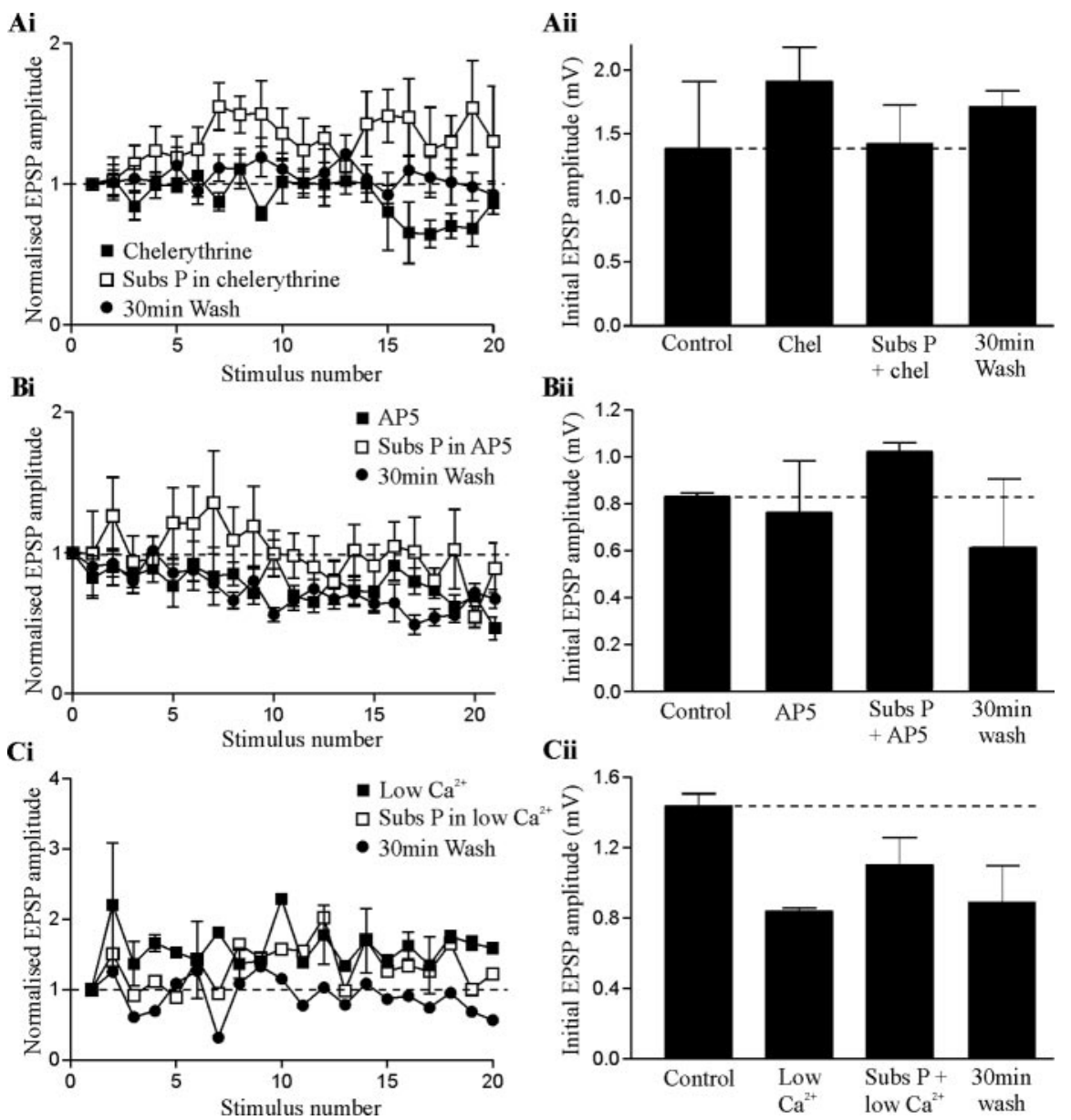

Figure 2. The metaplastic facilitation shares the same induction properties as the burst frequency modulation. Because the substance P-evoked metaplasticity is not necessarily evoked in all connections in control, presumably because of the variable properties of EIN synapses to motor neurons, graphs here and in Figure 3 only show the connections where any metaplastic facilitation occurred. Ai, Graph showing the plasticity evoked over $20 \mathrm{~Hz}$ spike trains in the presence of the PKC antagonist chelerythrine $(10 \mu \mathrm{m})$, in chelerythrine and substance $P($ Subs $P)$, and in chelerythrine 30 min after the start of substance $P$ wash-off $(n=5)$. Note that the metaplastic facilitation does not develop over the initial part of the spike train and recovers to control after washing for $30 \mathrm{~min}$. Aii, Graph showing the effect of chelerythrine (Chel) and substance P on the initial EPSP amplitude $(n=8)$. Note that chelerythrine nonsignificantly $(p>0.05)$ increased the amplitude of the initial EPSP in the spike train and that the addition of substance $P$ resulted in a nonsignificant reduction of the initial EPSP amplitude ( $p>0.05)$. Bi, Graph showing the plasticity evoked over $20 \mathrm{~Hz}$ spike trains in the presence of the NMDA receptor antagonist AP-5 (100 $\mu \mathrm{m} ; n=5)$, in AP-5 and substance $P(n=5)$, and in AP-5 30 min after the start of substance $P$ wash-off $(n=4)$. Bii, The effects of AP-5 and substance $P$ on the amplitude of the initial EPSP in the train ( $n=12$; all effects were nonsignificant; $p>0.05)$. Ci, Graph showing the plasticity evoked over $20 \mathrm{~Hz}$ spike trains in low-calcium Ringer's solution, in low-calcium Ringer's solution and substance $P$, and in lowcalcium Ringer's solution 30 min after the start of substance $P$ wash-off $(n=5)$. Cii, The effects of low-calcium Ringer's solution and substance $P$ on the amplitude of the initial EPSP in the spike train $(n=5)$.

and $4 \mathrm{hr}$ after $(n=35)$ substance $\mathrm{P}$ application. $E$, Schematic diagram showing the technique for stimulating identified EINS extracellularly. The traces show the synaptic input evoked by an EIN when a spike was evoked intracellularly on rebound from a hyperpolarizing current pulse, or when it was evoked by stimulating the cord (gray line; the stimulus artifact has been removed). The PSP in both cases was the same, suggesting that only the EIN recorded from had been stimulated. Fi, Graph showing the time course of the metaplastic facilitation (measured as the average of the 2nd to 5th EPSPs in the train) and the potentiation of the initial EPSP in experiments that used extracellular EIN stimulation $(n=4)$. Fii, Traces showing the initial EPSP amplitude and the metaplasticity in control and at different times after substance P application from a single experiment using extracellular EIN stimulation. The metaplastic facilitation is shown by the increase in the average of the second to fifth EPSPs in the train $3 \mathrm{hr}$ after substance P application. Gi, Gii, Substance P did not evoke metaplastic facilitation of reticulospinal-evoked inputs. Instead, depression was usually enhanced. This may be because of the increased amplitude of the initial EPSP in the spike train. The black trace shows the control response and the gray trace the response in substance $P$. The bottom voltage value on the scale bar refers to action potential amplitudes and the top value to EPSP amplitudes. synthesis was not needed for its maintenance at this time. Neither translation nor transcription inhibitors blocked the short-term potentiation of the initial EPSP amplitude by substance P (data not shown).

The difficulties associated with examining long-term effects on synaptic properties mean that the sample sizes of these experiments are relatively low. However, the results suggest that the initial maintenance of the metaplasticity requires protein, but not de novo mRNA synthesis, and thus shares the same features as the initial maintenance phase of the long-term network modulation.

\section{Effects of substance $P$ on synaptic properties}

Activity-dependent plasticity is usually associated with changes in the transmitter release probability (Zucker and Regehr, 2002): facilitation is usually associated with lower release probabilities and depression with higher release probabilities. The EINs show this relationship between release probability and activity-dependent plasticity; depressing connections have relatively high release probabilities and facilitating connections relatively low release probabilities (Parker, 2003). From this relationship, the switch from depression to facilitation by substance $\mathrm{P}$ would be expected to be associated with a reduction in release probability. This was examined using a V-M analysis (Clements and Silver, 2000) (see Materials and Methods). This method examines the PSP variance and mean under conditions of altered release probability (V-M analysis). At low release probabilities, fewer sites release transmitter, and the EPSP amplitude and variance are reduced. At high release probabilities, almost all sites release transmitter. This increases the EPSP amplitude but again reduces the variance. At intermediate release probabilities, the number of sites that release transmitter fluctuates from trial to trial. This results in intermediate EPSP amplitudes and an increased variance. The relationship of the variance to the mean at different release probabilities can be approximated by a parabola (for details, see Clements and Silver, 2000):

$$
y=A x-B x^{2},
$$

where $y$ is the PSP variance, and $x$ is the mean amplitude. $A$ and $B$ are free parameters that are adjusted to optimally fit the parabola to the V-M data. The quantal amplitude $\left(q_{\mathrm{w}}\right)$, release probability $\left(p_{\mathrm{w}}\right)$, 
$\mathbf{A}$

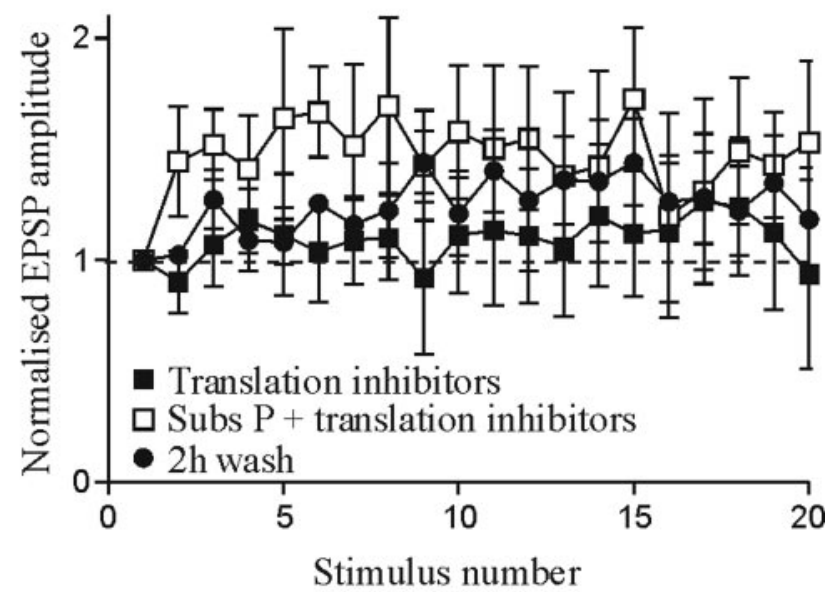

B

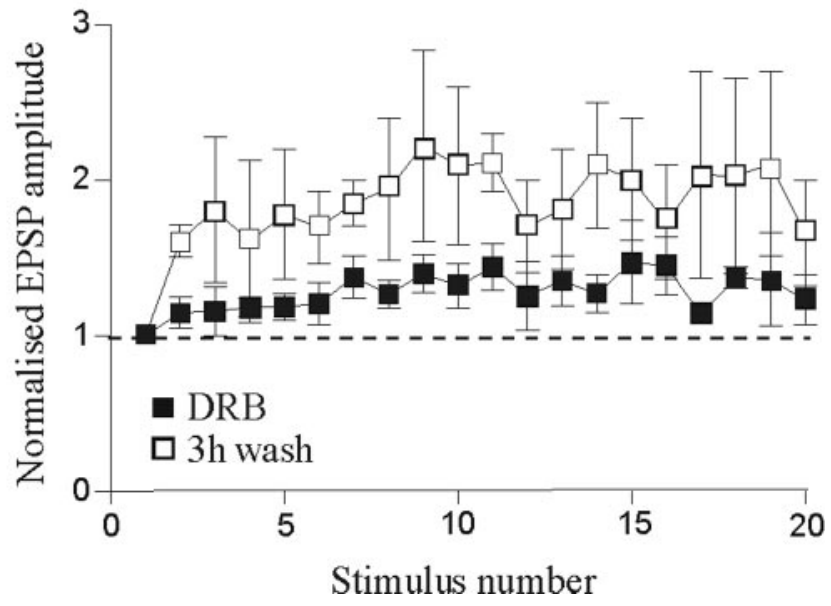

Figure 3. The metaplasticity is dependent on protein synthesis for its maintenance. A, Graph showing the plasticity evoked over $2 \mathrm{OHz}$ spike trains in the presence of the translation inhibitors anisomycin or puromycin $(10 \mu \mathrm{M})$, in anisomycin or puromycin and substance $P($ Subs $P)$, and in anisomycin or puromycin $2 \mathrm{hr}$ after the start of substance $P$ wash-off $(n=5)$. B, Graph showing the plasticity evoked over $20 \mathrm{~Hz}$ spike trains in the presence of the transcription inhibitor DRB $(10 \mu \mathrm{M})$ and in DRB $3 \mathrm{hr}$ after the start of substance P wash-off $(n=4)$. Note that the metaplasticity persists $2-3 \mathrm{hr}$ after substance $P$ application after blocking transcription but does not persist at this time after blocking translation.

and number of release sites $\left(n_{\min }\right)$ can then be calculated as follows:

$$
\begin{gathered}
q_{\mathrm{w}}=A /\left(1+C V^{2}\right), \\
p_{\mathrm{w}}=x(B / A)\left(1+C V^{2}\right), \\
n_{\min }=1 / B .
\end{gathered}
$$

$q_{\mathrm{w}}$ and $p_{\mathrm{w}}$ are weighted averages (i.e., they emphasize terminals with larger quantal amplitudes and release probabilities), whereas $n_{\min }$ is the minimum number of release sites.

Separate EINs to motor neuron connections were examined in normal Ringer's solution and low- and high-calcium Ringer's solution in control $(n=7)$ and $4 \mathrm{hr}$ after substance $\mathrm{P}$ application $(n=7)$ (Fig. 4Ai,Aii). The release probability $\left(p_{\mathrm{w}}\right)$, minimum number of release sites $\left(N_{\mathrm{min}}\right)$, and the quantal amplitude $\left(q_{\mathrm{w}}\right)$ were compared at the two times.

Substance $\mathrm{P}$ reduced the transmitter release probability from $0.55 \pm 0.05$ in control to $0.32 \pm 0.014 \mathrm{hr}$ after substance $\mathrm{P}$
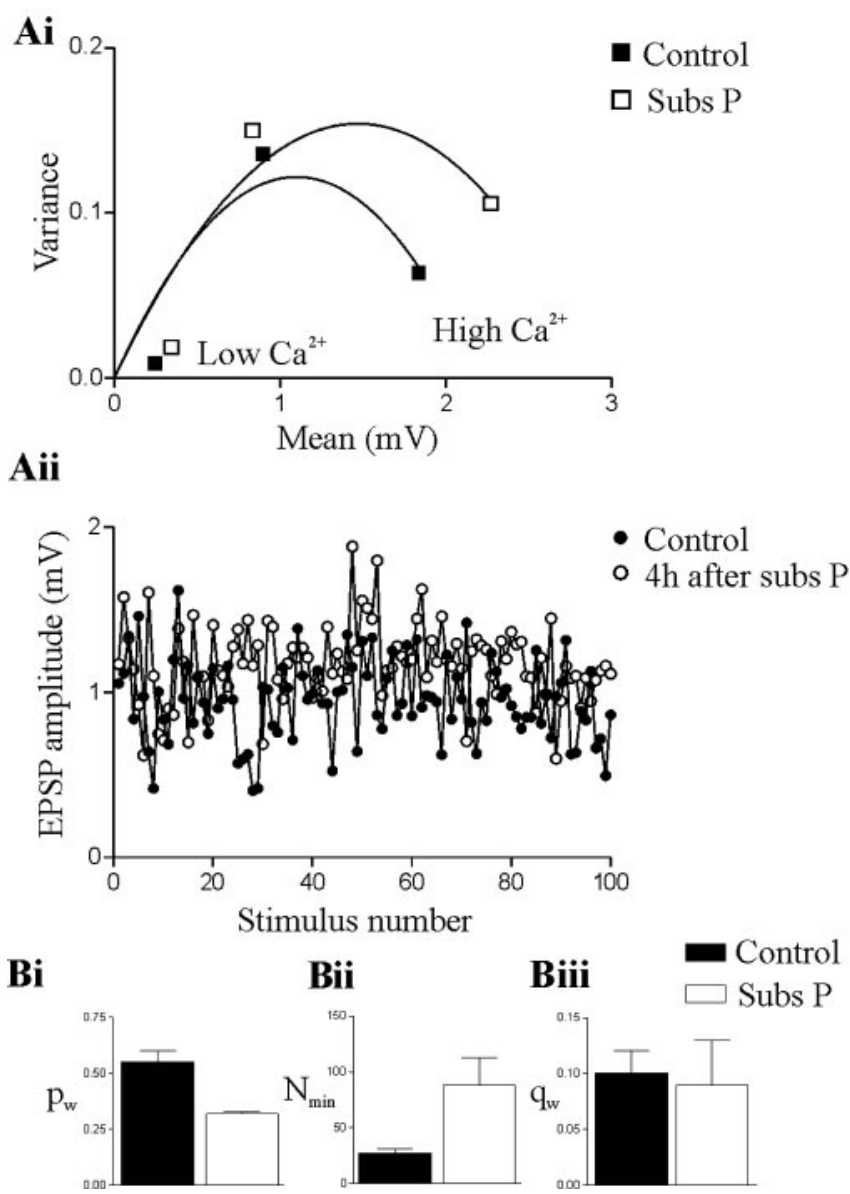

Figure 4. A V-M analysis of EIN-evoked synaptic transmission to motor neurons in control $(n=7)$ and $4 \mathrm{hr}$ after substance $\mathrm{P}$ (Subs $\mathrm{P})$ application $(n=7) . A i$, The relationship of the mean and variance of EIN-evoked EPSPs in normal Ringer's solution, high-calcium Ringer's solution, and low-calcium Ringer's solution is shown. Low-calcium Ringer's solution reduced the mean EPSP amplitude and variance, whereas high-calcium Ringer's solution increased the EPSP amplitude but reduced the EPSP variance. Each point represents the mean and variance of 100 EPSPs evoked at $0.2 \mathrm{~Hz}$ in one connection in control and in one connection after substance $P$ application. A parabolic fit connects the points. Aii, Graph showing the absence of any activitydependent change in the synaptic input over the $0.2 \mathrm{~Hz}$ stimulation period. The bar graphs show the release probability $\left(p_{w} ; B i\right)$, minimum number of release sites $\left(N_{\min } ; B i i\right)$, and the quantal amplitude $\left(q_{\mathrm{w}} ;\right.$ Biii) in control connections and in connections examined $4 \mathrm{hr}$ after substance $P$ application.

application $(p<0.05 ; n=7)$ (Fig. $4 \mathrm{Bi}$ ). It also significantly increased the number of release sites from $27 \pm 4$ in control to $88 \pm 254 \mathrm{hr}$ after substance $\mathrm{P}$ application $(p<0.05 ; n=7$ ) (Fig. $4 \mathrm{Bii}$. There was, however, no significant difference in the quantal amplitude in control or $4 \mathrm{hr}$ after substance $\mathrm{P}$ application $(0.10 \pm 0.04 \mathrm{mV}$ and $0.089 \pm 0.05 \mathrm{mV}$, respectively; $p>0.05 ; n=$ 7) (Fig. 4 Biii), which suggests against a long-term effect of substance $\mathrm{P}$ on postsynaptic properties.

These results suggest that the metaplasticity reflects a reduction in release probability, which will allow the development of facilitation during spike trains. However, this effect alone would not be consistent with the development of facilitation in the absence of a reduction in the initial EPSP amplitude. The increase in the number of release sites may provide a mechanism that allows facilitation to develop without a reduction of the initial EPSP amplitude (see Discussion). 

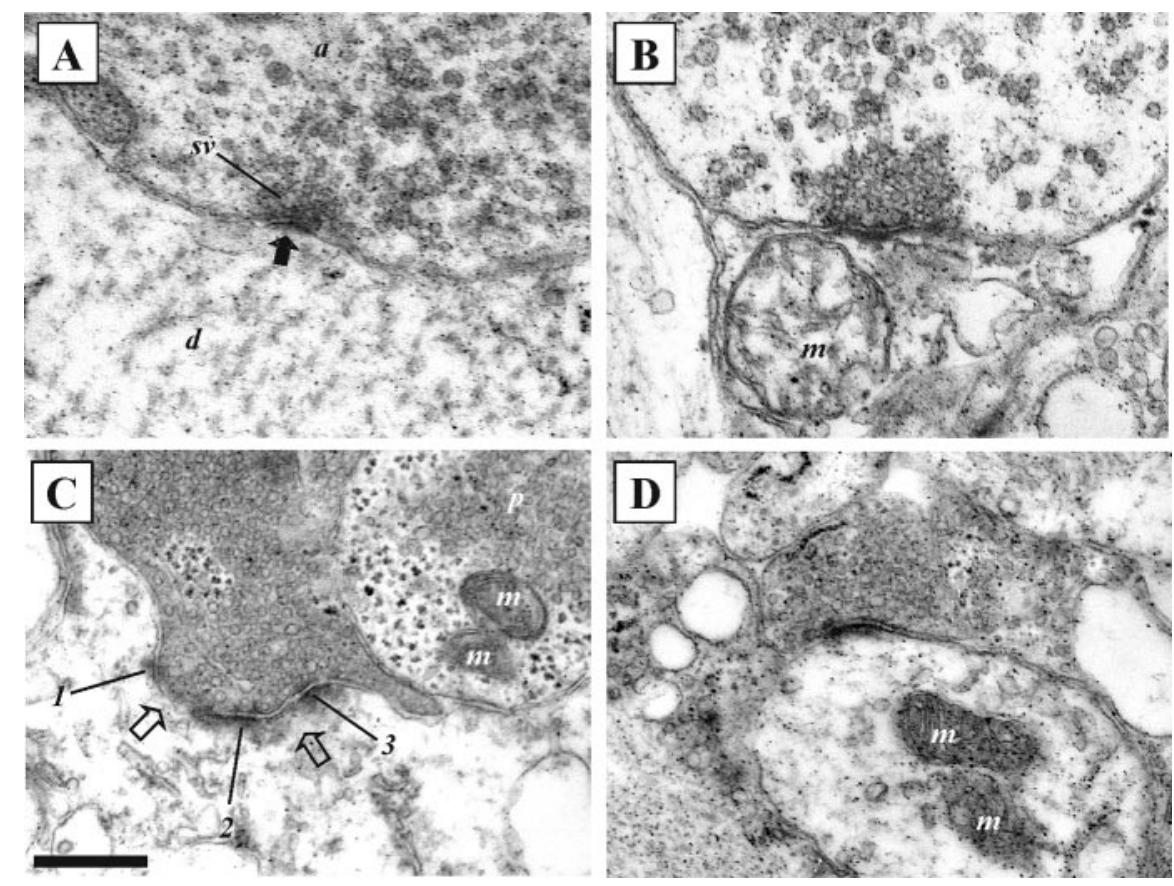

Figure 5. Electron micrographs showing examples of synaptic morphology before and at different times after substance $P$ application. $A$, Example of an asymmetric synapse with round vesicles in a spinal cord that had not been exposed to substance $P$. The solid black arrow indicates the PSD. B, An asymmetric synapse with round vesicles 30 min after substance Papplication. C, An asymmetric synapse with two perforations (open arrows) and round vesicles $3 \mathrm{hr}$ after substance $P$ application. Numbers $1-3$ indicate regions of the PSD. A neighboring axon contains pleomorphic vesicles (p; vesicles with irregular shapes and sizes). D, An asymmetric synapse with round vesicles $5 \mathrm{hr}$ after substance $\mathrm{P}$ application. a, Axon; d, dendrite; m, mitochondria; sv, synaptic vesicles. Scale bar, $250 \mathrm{~nm}$.

\section{Changes in synaptic ultrastructure}

The duration of the metaplasticity and its induction and maintenance properties suggest that it could contribute to the long-term modulation of the network burst frequency. Long-term changes in synaptic function are often associated with changes in synaptic organization (Lisman and Harris, 1993). We have thus also examined the effects of substance $P$ on synaptic ultrastructure (see Materials and Methods) (Figs. 5, 6).

\section{Synaptic vesicles}

The number of docked vesicles (i.e., vesicles in contact with the presynaptic membrane at the release site) was significantly increased $30 \mathrm{~min}, 3 \mathrm{hr}$, and $5 \mathrm{hr}$ after substance P application (Fig. $6 A$ ). The total number of synaptic vesicles varied widely in control and after substance $\mathrm{P}$ application (range, 6-600). There was no significant difference in the number of total vesicles in control or at different times after substance $\mathrm{P}$ application (control, $140 \pm$ 14; $30 \mathrm{~min}, 137 \pm 13 ; 3 \mathrm{hr}, 107 \pm 9 ; 5 \mathrm{hr}, 110 \pm 9 ; p>0.05)$. Substance $\mathrm{P}$ also had no significant effect on the vesicle diameter (data not shown).

Although the number of docked vesicles was significantly increased when all synapses were grouped, the effect was dependent on the type of synapse examined (Fig. $6 B-E$ ). In cords fixed 30 min after substance $P$ application, there was a significant increase in docked vesicles at synapses that were asymmetric and simple (Fig. 6C,D); by $3 \mathrm{hr}$ after substance $\mathrm{P}$ application, the effect was only significant at simple synapses or synapses that contained round vesicles (Fig. $6 B, D$ ), and by $5 \mathrm{hr}$ a significant increase in docked vesicles occurred at simple, asymmetric synapses that contained round vesicles and were made onto dendritic shafts (Fig. 6B-E). These synapses formed the largest proportion of connections in the total sample, which presumably accounted for the significant increase in the number of docked vesicles when all synapses were grouped.

In addition to the increase in the total number of docked vesicles, the number of docked vesicles per $100 \mathrm{~nm}$ of PSD was significantly increased $5 \mathrm{hr}$ after substance $\mathrm{P}$ application (from $1.05 \pm 0.07$ to $1.50 \pm$ $0.1 ; p<0.001$; data not shown). This matches the effect of BDNF on excitatory synapses in the hippocampus and suggests that substance $\mathrm{P}$ increased the density of vesicles at the active zone (Tyler and Pozzo-Miller, 2001).

\section{Effects on synaptic organization}

Several studies have suggested that longterm changes in synaptic properties are associated with the enlargement or perforation of synapses (Marrone and Petit, 2002) (but see Sorra et al., 1998). There was a nonsignificant increase in the total length of the PSD when all synapses were grouped at $30 \mathrm{~min}$ and $5 \mathrm{hr}$, but not $3 \mathrm{hr}$, after substance $\mathrm{P}$ application (data not shown). There was, however, a significant increase in the proportion of perforated synapses at asymmetric synapses $3 \mathrm{hr}$, but not $30 \mathrm{~min}$ or $5 \mathrm{hr}$, after substance $\mathrm{P}$ application (from 28 to $48 \%$; $p<0.05$ ) (Table 1, Fig. $5 C$ ). The proportion of perforated synapses was nonsignificantly increased at symmetrical synapses $3 \mathrm{hr}$ after substance P application (from 33 to $50 \%$; $p>$ $0.05)$.

In addition to changes in the PSD, substance $\mathrm{P}$ also resulted in a significant decrease in the synaptic gap $5 \mathrm{hr}$, but not $30 \mathrm{~min}$ or 3 hr, after substance $\mathrm{P}$ application (Fig. $6 F$ ). This effect was significant at both symmetrical $(p<0.05)$ and asymmetrical synapses $(p<0.001$; asymmetric from $20.6 \pm 0.5 \mathrm{~nm}$ in control to $17.6 \pm$ $0.4 \mathrm{~nm}$; symmetric from $20.2 \pm 0.5 \mathrm{~nm}$ in control to $18.0 \pm 0.7$ nm; data not shown).

Substance P had no significant effect on the vesicle morphology or the number of presynaptic mitochondria (data not shown). There was a trend to an increase in the number of postsynaptic mitochondria at asymmetric synapses $3 \mathrm{hr}$ after substance $\mathrm{P}$ application, but this effect was not significant $(p>$ 0.05; data not shown).

\section{Discussion}

These results show that substance $P$ evokes long-term metaplastic facilitation of glutamatergic synaptic transmission and alters synaptic ultrastructure. These effects could provide a functional and morphological basis for the long-term network modulation.

\section{Relationship of metaplasticity to the network modulation}

The analysis of metaplasticity was complicated by the requirement of making long-term recordings from the EINs. Synaptic properties were thus compared in different connections before and $4 \mathrm{hr}$ after substance $\mathrm{P}$ application. Because long-term intracellular recordings were impossible, the long-term analysis of individual connections was only possible using extracellular EIN simulation, a technique that had relatively limited success. The 


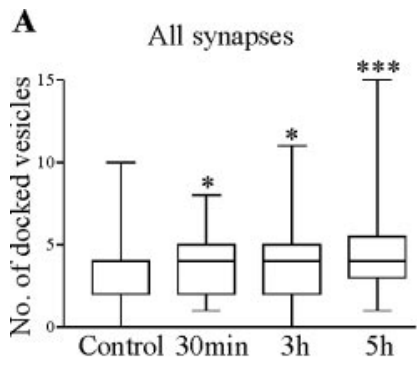

B Synapses with round vesicles
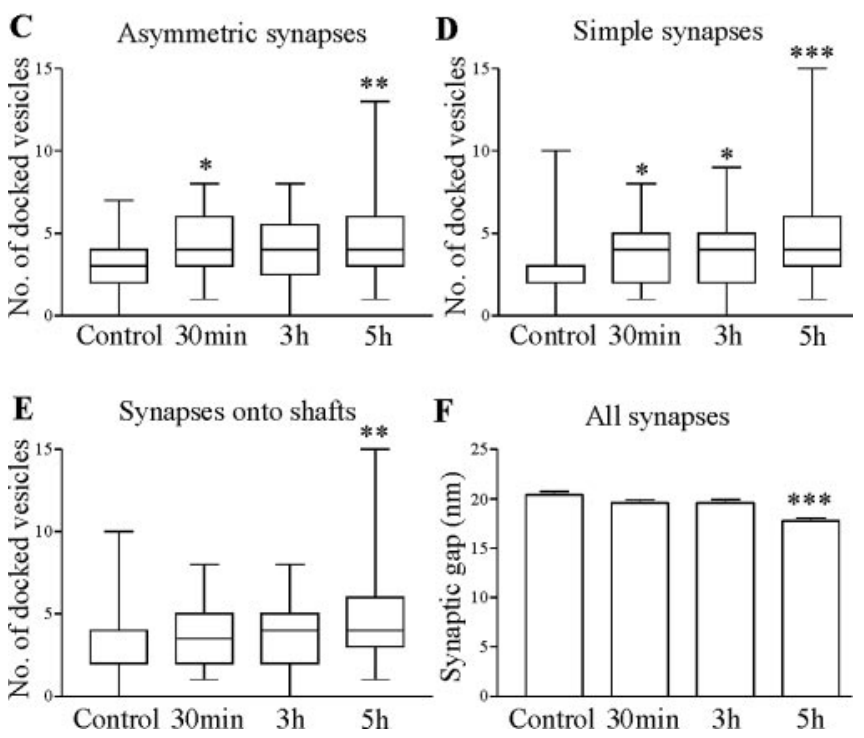

Figure 6. Substance $P$ increased the number of docked vesicles and reduced the synaptic gap. $A$, Graph showing the number of docked vesicles at all synapses at different times after substance $P$ application. Graphs showing the number of docked vesicles at synapses with round vesicles $(B)$, asymmetric synapses $(C$, simple synapses $(D)$, and synapses made onto dendritic shafts $(E)$. $F$, Graph showing the distance across the synaptic gap at different times after substance $P$ application. $A-E$, Pooled data: control, $n=4$ animals; $30 \mathrm{~min}, n=4$ animals; $3 \mathrm{hr}, n=$ 3 animals; $5 \mathrm{hr}, n=4$ animals. F, Pooled data: control, $n=5$ animals; $30 \mathrm{~min}, n=4$ animals; $3 \mathrm{hr}, n=4$ animals; $5 \mathrm{hr}, n=4$ animals. ${ }^{*} p<0.05 ;{ }^{* *} p<0.01$; ${ }^{* * *} p<0.001$.

Table 1. Percentage of synapses perforated after substance $P$ application

\begin{tabular}{lllll}
\hline & \multicolumn{4}{l}{ lime after substance P application } \\
\cline { 2 - 4 } Type of synapse & Control & $30 \mathrm{~min}$ & $3 \mathrm{hr}$ & \\
\hline All & $33(104)$ & $42(71)$ & $52^{a}(85)$ & $42(92)$ \\
Symmetrical & $33(33)$ & $43(14)$ & $50(26)$ & $38(24)$ \\
Intermediate & $50(14)$ & $50(16)$ & $69(13)$ & $42(19)$ \\
Asymmetrical & $28(57)$ & $39(41)$ & $48^{a}(46)$ & $45(49)$ \\
\hline
\end{tabular}

The numbers in parentheses indicate the total number of observations within the group.

${ }^{a}$ Percentages of synapses perforated at $3 \mathrm{hr}$ in both the All and Asymmetrical synapse groups were significantly greater $(p<0.05)$ than the corresponding controls, calculated using Fisher's exact test.

results of both approaches, however, suggest that the metaplasticity persisted into the protein synthesis-dependent maintenance phase of the network burst frequency modulation, making it the only identified cellular or synaptic effect of substance P to last this long. In addition to its time course, the metaplasticity shared the induction and maintenance properties of the network modulation (Parker, 2000a), which further supports its role in the long-term network modulation.

\section{Changes in synaptic ultrastructure}

Synaptic function is influenced by synaptic ultrastructure (Pierce and Lewin, 1994; Sorra et al., 1998; Bailey, 1999; Neuhoff et al., 1999). Substance P altered several ultrastructural properties. The effects occurred predominantly at asymmetric synapses. These are usually considered to be glutamatergic (Peters et al., 1991), which is consistent with the effect of substance P on glutamatergic synaptic transmission (Parker, 2000a).

Substance P increased the number of docked vesicles. These are assumed to represent the readily releasable vesicle pool (Südhof, 2000). An increase in this pool is consistent with the increased frequency of miniature EPSPs after substance P application (Parker and Grillner, 1998).

The number of perforated synapses was increased $3 \mathrm{hr}$ after substance $\mathrm{P}$ application. Perforated synapses are thought to have a higher efficacy per unit area of active zone than nonperforated synapses (Marrone and Petit, 2002). However, an increase in perforations was not seen at $5 \mathrm{hr}$. The perforations that developed at $3 \mathrm{hr}$ may either have returned to the unperforated state by $5 \mathrm{hr}$, or perforated synapses may have split to form two distinct synapses (Marrone and Petit, 2002). Perforations also develop after repetitive stimulation of lamprey reticulospinal axons because of the expansion of the presynaptic membrane as a result of enhanced exocytosis (Shupliakov et al., 1997). The increase in perforations at $3 \mathrm{hr}$ may thus reflect a transient effect, not the cause, of the synaptic modulation.

While perforated synapses were only increased at $3 \mathrm{hr}$, by $5 \mathrm{hr}$ there was a significant reduction in the synaptic gap. These changing effects may suggest an orchestrated sequence of structural changes at different times after substance $P$ application. This could reflect the need for stability with change, allowing different aspects of synaptic organization to be altered without disrupting ongoing synaptic and network function.

The interpretation of the ultrastructural data must take into account our use of non-serial sections. These have been used to examine the ultrastructural effects of activity and neurotrophinmediated plasticity (Buchs and Muller, 1996; Neuhoff et al., 1999; Tyler and Pozzo-Miller, 2001). Although non-serial sections could introduce errors in the estimates of synaptic properties (Calverley and Jones, 1987), these errors will affect control and substance $\mathrm{P}$ groups equally and thus should not affect our conclusions. In addition, estimates of the number of docked vesicles from non-serial sections have shown results that are in agreement with the results obtained from serial sections (Tyler and PozzoMiller, 2001).

\section{Metaplasticity mechanisms}

Facilitation and depression are usually associated with low and high initial release probabilities, respectively (Zucker and Regehr, 2002). The EINs also show this relationship: depressing connections have relatively high release probabilities and facilitating connections relatively low release probabilities (Parker, 2003).

The EPSP amplitude is a function of the quantal amplitude ( $q$; the postsynaptic response to a single transmitter vesicle) and the quantal content ( $m$; the number of vesicles released). The quantal content in turn is a function of the release probability $(p)$ and $n$, which can represent the number of synaptic terminals, the number of release sites, or the number of releasable vesicles ( $m=n p$; thus the EPSP amplitude =npq) (Thomson, 2000; Zucker and Regehr, 2002). Because the depression and facilitation of EIN inputs is associated with high and low release probabilities, respectively (Parker, 2003), the metaplastic facilitation could reflect a switch from a high $p$ (depressing) to a low $p$ (facilitating) state. This was supported by the V-M analysis, which showed a reduction of release probability $4 \mathrm{hr}$ after substance $\mathrm{P}$ application. However, a reduction in $p$ alone would reduce the quantal content and thus reduce the initial EPSP amplitude, an effect that is 
not normally associated with the substance P-mediated synaptic modulation. Because the EPSP amplitude is determined by $n p q$, the initial EPSP could remain at the control amplitude despite a reduced $p$ if there was a compensatory increase in either $q$ or $n$. Previous studies suggested against a long-term change in $q$ (Parker, 2000a). This was supported by the V-M analysis performed here, which failed to show a significant change in $q 4 \mathrm{hr}$ after substance $\mathrm{P}$ application. However, the increase in docked vesicles identified in the ultrastructural analysis could provide a morphological correlate of an increased $n$, which could maintain the initial EPSP amplitude at the control value despite the reduced $p$. The $\mathrm{V}-\mathrm{M}$ analysis also suggests a significant increase in the number of release sites $\left(N_{\min }\right)$. This could reflect the formation of new release sites, perhaps resulting from synapse perforation and splitting. Alternatively, the increase in docked vesicles could convert silent synapses that lack docked vesicles into functional connections, and thus increase $N_{\text {min }}$. These effects have not been examined here.

Parallel changes in functional and structural properties could thus influence the long-term synaptic and network modulation. The simplest interpretation of the morphological and physiological data suggests that the metaplasticity is mediated presynaptically through changes in the transmitter release probability or the number of release sites. However, its induction is NMDA receptor dependent, which suggests a postsynaptic effect (Parker and Grillner, 1998). The conversion of postsynaptic induction into presynaptic maintenance would require a retrograde factor that converts postsynaptic induction into presynaptic maintenance (Hawkins et al., 1998). Alternatively, the NMDA-dependent induction of the network modulation may reflect an effect on NMDA receptors on presynaptic terminals, which can influence synaptic transmission from lamprey reticulospinal axons (Cochilla and Alford, 1999). These effects remain to be examined.

\section{Role of the metaplasticity}

Facilitation is usually associated with lower release probabilities and smaller initial EPSP amplitudes (Zucker and Regehr, 2002). However, if facilitation developed from a smaller initial EPSP, it would not necessarily increase the synaptic input to motor neurons during spike bursts. For example, 5-HT facilitates EIN inputs during spike trains (Parker, 2000a), but this facilitation develops from a reduction in the initial EPSP amplitude (Fig. 7). As a result, the net synaptic input during network activity is reduced over physiologically relevant spike trains (up to five spikes at 5-30 $\mathrm{Hz}$ ). In contrast, the substance P-evoked metaplastic facilitation that develops without a reduction in the initial EPSP amplitude results in a $150-200 \%$ increase in the glutamatergic input to motor neurons over physiologically relevant spike trains (Fig. 7). Parallel changes in release probability and $n$ (e.g., the number of release sites or docked vesicles) thus allow facilitation to develop without a reduction of the initial EPSP amplitude, resulting in an increase in the excitatory drive to motor neurons.

An increase in glutamatergic drive increases the network burst frequency both experimentally and in computer simulations (Brodin et al., 1985; Hellgren et al., 1992). The metaplasticity of EIN transmission will increase glutamatergic transmission in the network, and thus the effect is superficially consistent with the increased frequency of network activity. However, the EIN connection to motor neurons is probably not involved in determining the frequency of network activity, which will instead depend on the interactions between network interneurons (but see Buchanan, 1999, for a role for motor neurons in patterning network activity). As in modulatory effects described in other sys-

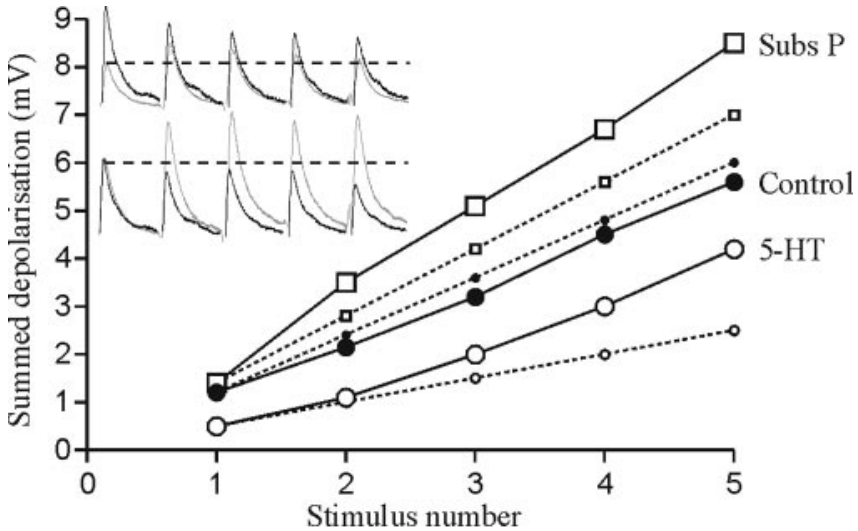

Figure 7. The effect of activity-dependent facilitation on the summed EIN synaptic input over physiologically relevant trains of five spikes at $20 \mathrm{~Hz}$ in $5-\mathrm{HT}$, which reduced the initial EPSP amplitude (Parker, 2000a), and in substance P (Subs P), which facilitated the connection without reducing the initial EPSP amplitude. The dashed lines with smaller symbols show the extrapolated summed input assuming no activity-dependent plasticity during the spike train. Note that the substance P-mediated facilitation results in a net increase in the glutamatergic input compared with control over all regions of the spike train, whereas the 5-HT-evoked facilitation is associated with a net reduction of the glutamatergic input over all regions of the spike train. Traces on the graph illustrate the effects of 5-HT (top set of traces) and substance P (bottom set of traces).

tems (Harris-Warrick et al., 1998), the effects of substance P are dependent on the type of cell or synapse examined, and thus its effects cannot be extrapolated to other types of network synapses. The metaplastic effects of substance P on connections between interneurons are being examined, but the sample sizes are not yet large enough to determine the significance of the effects. Instead of increasing the frequency of network activity, the metaplasticity of EIN inputs to motor neurons may serve to potentiate motor neuron activity over spike bursts to ensure that sufficient muscle tension is generated. This is necessary because the increase in the frequency of the network output is associated with a reduction of the burst duration. This will limit the time over which motor neurons are active, and thus the time over which muscle tension can develop. By increasing the excitatory input to motor neurons, the metaplastic facilitation will increase motor neuron activity over the shorter burst duration and thus help to ensure that sufficient muscle tension is generated. Ongoing analyses of the effects of substance $P$ in different developmental stages suggests that these effects may be related to the migratory phase of the animal, in which the animal swims long distances to mate (Parker, unpublished observations).

\section{References}

Abraham W, Bear M (1996) Metaplasticity: the plasticity of synaptic plasticity. Trends Neurosci 19:126-130.

Bailey C (1999) Structural changes and the storage of long-term memory. Can J Physiol Pharmacol 77:738-747.

Bailey C, Bartsch D, Kandel E (1996) Toward a molecular definition of longterm memory storage. Proc Natl Acad Sci USA 93:13445-13452.

Bear MF, Malenka RC (1994) Synaptic plasticity: LTP and LTD. Curr Opin Neurobiol 4:389-399.

Brodin L, Grillner S, Rovainen C (1985) N-methyl-D-aspartate (NMDA), kainate and quisqualate receptors and the generation of fictive locomotion in the lamprey spinal cord. Brain Res 325:302-306.

Buchanan J (1999) The roles of interneurons and motoneurons in the lamprey locomotor network. Prog Brain Res 123:311-321.

Buchanan J, Cohen A (1982) Activities of identfied interneurones, motoneurones and muscle fibres during fictive swimming in the lamprey and effects of reticulospinal and dorsal cell stimulation. J Neurophysiol 47:948-960. 
Buchanan J, Kasicki S (1995) Activities of spinal neurons during brain stemdependent fictive swimming in lamprey. J Neurophysiol 73:80-87.

Buchanan JT, Grillner S, Cullheim S, Risling M (1989) Identification of excitatory interneurons contributing to generation of locomotion in lamprey: structure, pharmacology, and function. J Neurophysiol 62:59-69.

Buchs P-A, Muller D (1996) Induction of long-term potentiation is associated with major ultrastructural changes of activated synapses. Proc Natl Acad Sci USA 93:8040-8045.

Calverley R, Jones D (1987) Determination of the numerical density of perforated synapses in rat neocortex. Cell Tissue Res 248:399-407.

Chen R, Cohen L, Hallett M (2002) Nervous system reorganization following injury. Neuroscience 111:761-773.

Clements J, Silver R (2000) Unveiling synaptic plasticity: a new graphical and analytical approach. Trends Neurosci 23:105-113.

Cochilla A, Alford S (1999) NMDA receptor-mediated control of preysnaptic calcium and neurotransmitter release. J Neurosci 19:193-205.

Feldman D, Nicoll R, Malenka R (1999) Synaptic plasticity at thalamocortical synapses in developing rat somatosensory cortex: LTP, LTD, and silent synapses. J Neurobiol 41:92-101.

Harris-Warrick R, Johnson B, Peck J, Kloppenburg P, Ayali A, Skarbinski J (1998) Distributed efects of dopamine modulation in the crustacean pyloric network. Ann NY Acad Sci 860:155-167.

Hawkins R, Son H, Arancio O (1998) Nitric oxide as a retrograde messenger during long-term potentiation in hippocampus. Prog Brain Res 118:155-172.

Hellgren J, Grillner S, Lansner A (1992) Computer simulation of the segmental neural network generating locomotion in lamprey by using populations of network interneurons. Biol Cybern 68:1-13.

Lisman J, Harris K (1993) Quantal analysis and synaptic anatomy-integrating two views of hippocampal plasticity. Trends Neurosci 16:141-147.

Malenka R, Nicoll R (1999) Long-term potentiation—a decade of progress? Science 285:1870-1874.

Marrone D, Petit T (2002) The role of synaptic morphology in neural plasticity: structural interactions underlying synaptic power. Brain Res Rev 38:291-308.

Martin S, Grimwood P, Morris R (2000) Synaptic plasticity and memory: an evaluation of the hypothesis. Annu Rev Neurosci 23:649-711.

Milner B, Squire L, Kandel E (1998) Cognitive neuroscience and the study of memory. Neuron 20:445-468.

Neuhoff H, Roeper J, Schweizer M (1999) Activity-dependent formation of perforated synapses in cultured hippocampal neurons. Eur J Neurosci 11:4241-4250.

Parker D (2000a) Spinal cord plasticity: independent and interactive effects of neuromodulator and activity-dependent plasticity. Mol Neurobiol 21:1-26.

Parker D (2000b) Activity and calcium-dependent mechanisms maintain excitatory synaptic transmission in a rhythmic network. J Neurosci 20:1754-1766.

Parker D (2003) Variable properties in a single class of excitatory spinal synapse. J Neurosci 23:3154-3163.

Parker D, Grillner S (1998) Cellular and synaptic modulation underlying substance P-mediated plasticity of the lamprey locomotor network. J Neurosci 18:8095-8110.

Parker D, Grillner S (1999a) Long-lasting substance P-mediated modulation of NMDA-induced rhythmic activity in the lamprey locomotor network involves separate protein and RNA synthesis-dependent stages. Eur J Neurosci 11:1515-1522.

Parker D, Grillner S (1999b) Activity-dependent metaplasticity of inhibitory and excitatory synaptic transmission in the lamprey spinal cord locomotor network. J Neurosci 19:1647-1656.

Parker D, Zhang W, Grillner S (1998) Substance P modulates NMDA responses and causes long-term protein synthesis-dependent modulation of the lamprey locomotor network. J Neurosci 18:4800-4813.

Peters A, Palay S, Webster H (1991) Fine structure of the nervous system: neurons and their supporting cells, Ed 3. New York: Oxford UP.

Pierce J, Lewin G (1994) An ultrastructural size principle. Neuroscience 58:441-446.

Shupliakov O, Low P, Grabs D, Gad H, Chen H, David C, Takei K, De Camilli P, Brodin L (1997) Synaptic vesicle endocytosis impaired by disruption of dynamin-SH3 domain interactions. Science 276:259-263.

Sorra K, Fiala J, Harris K (1998) Critical assessment of the involvement of perforations, spinules, and spine branching in hippocampal synapse formation. J Comp Neurol 398:225-240.

Südhof T (2000) The synaptic vesicle cycle revisited. Neuron 28:317-320.

Thomson A (2000) Molecular frequency filters at central synapses. Prog Neurobiol 62:159-196.

Tyler WJ, Pozzo-Miller LD (2001) BDNF enhances quantal neurotransmitter release and increases the number of docked vesicles at the active zones of hippocampal excitatory synapses. J Neurosci 21:4249-4258.

Zucker RS, Regehr WG (2002) Short-term synaptic plasticity. Annu Rev Physiol 64:355-405. 